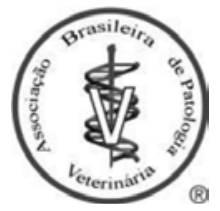

Diagnostic Exercise

From The Latin Comparative Pathology Group*

\title{
Chronic pyrrolizidine alkaloid toxicosis in a heifer
}

\author{
Contributors:
}

Vanessa Barraza ${ }^{1}$, Mariana Martins Flores ${ }^{1 *}$.

${ }^{1}$ Laboratory of Veterinary Pathology, Universidade Federal de Santa Maria (UFSM), Santa Maria, Rio Grande do Sul, Brazil, **Corresponding author: E-mail: mariana.flores@ufsm.br

\section{Clinical History:}

This heifer came from a group of cattle with chronic diarrhea and emaciation. Some of the animals also had neurological signs, predominantly aggressiveness. Two animals had already died spontaneously after worsening of the clinical signs. The farmer had kept these animals on native pasture during the winter, and he reported that the vegetation had been scarce in that period. On clinical exam, the animals were in bad body condition, with some presenting dyspnea, subcutaneous edema mainly affecting the dewlap, and abdominal distention.

\section{Necropsy and Microscopic Findings:}

There was marked subcutaneous edema, and the abdominal and thoracic cavities were filled with abundant translucent and slightly yellow effusion (Fig. 1). Additionally, there was mesenteric edema, and the liver was reduced in size, with a diffusely grayish capsular surface and firm consistency (Fig. 2). Histologically, multiple chronic alterations were seen in the liver (Figs. 3-5).

\section{Follow-up questions:}

- What is your morphologic diagnosis?

- What is the mechanism for the cavitary effusions?

- What histologic lesions would you expect to see in the CNS?

- Can you name three possible causes of liver fibrosis in cattle?

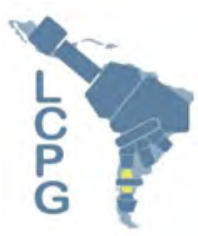

*The Diagnostic Exercises are an initiative of the Latin Comparative Pathology Group (LCPG), the Latin American subdivision of The Davis-Thompson Foundation and published in cooperation with the Brazilian Journal of Veterinary Pathology.

Editor-in-chief for this Diagnostic Exercise: Claudio Barros Associate Editor for this Diagnostic Exercise: Mariana M. Flores 
Diagnostic exercise From The Latin Comparative Pathology Group and

Braz J Vet Pathol, 2021, 14(3), 206 - 209

Gross and Microscopic Images:

DOI: 10.24070/bjvp.1983-0246.v14i3p206-209

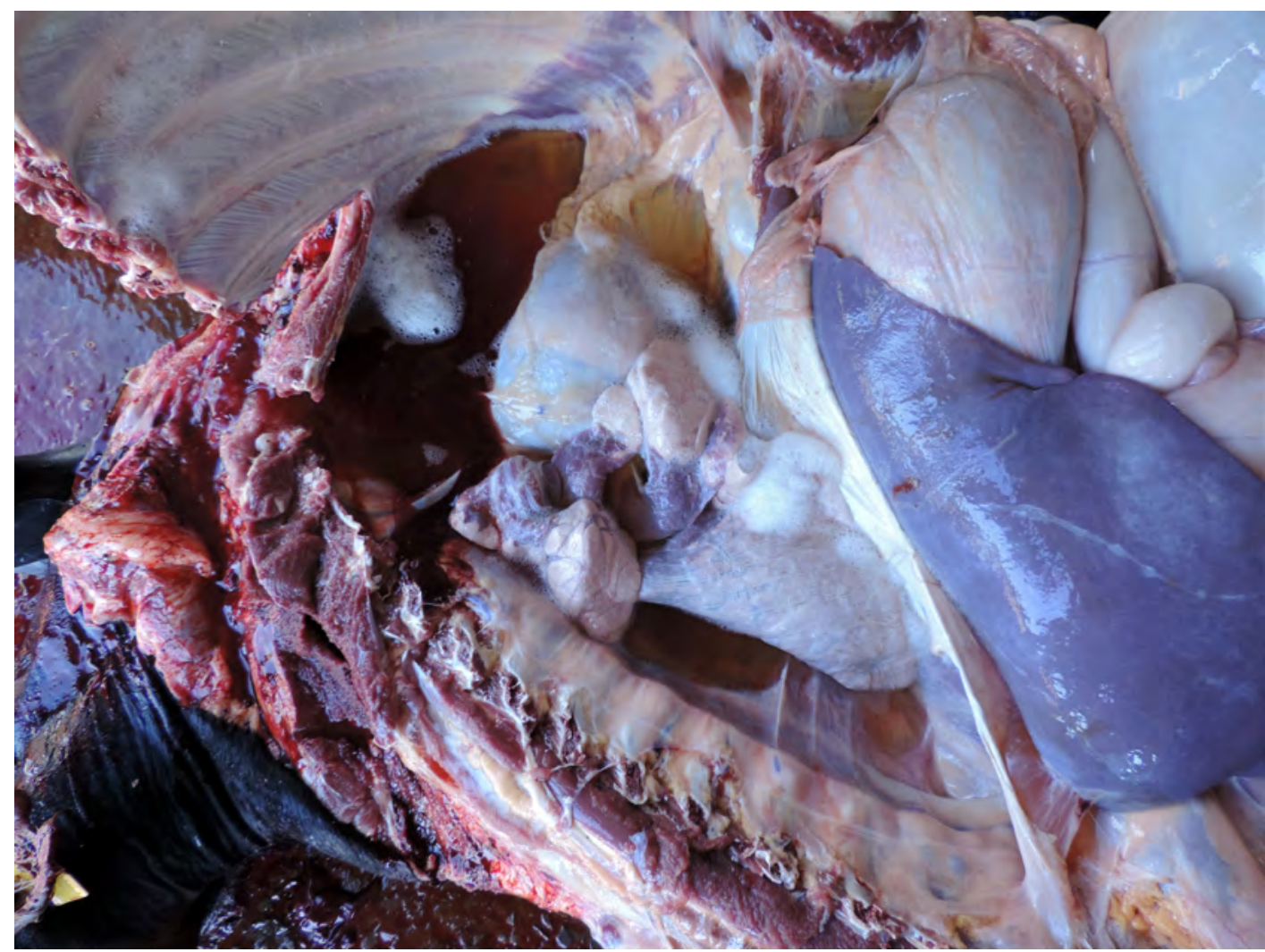

Figure 1

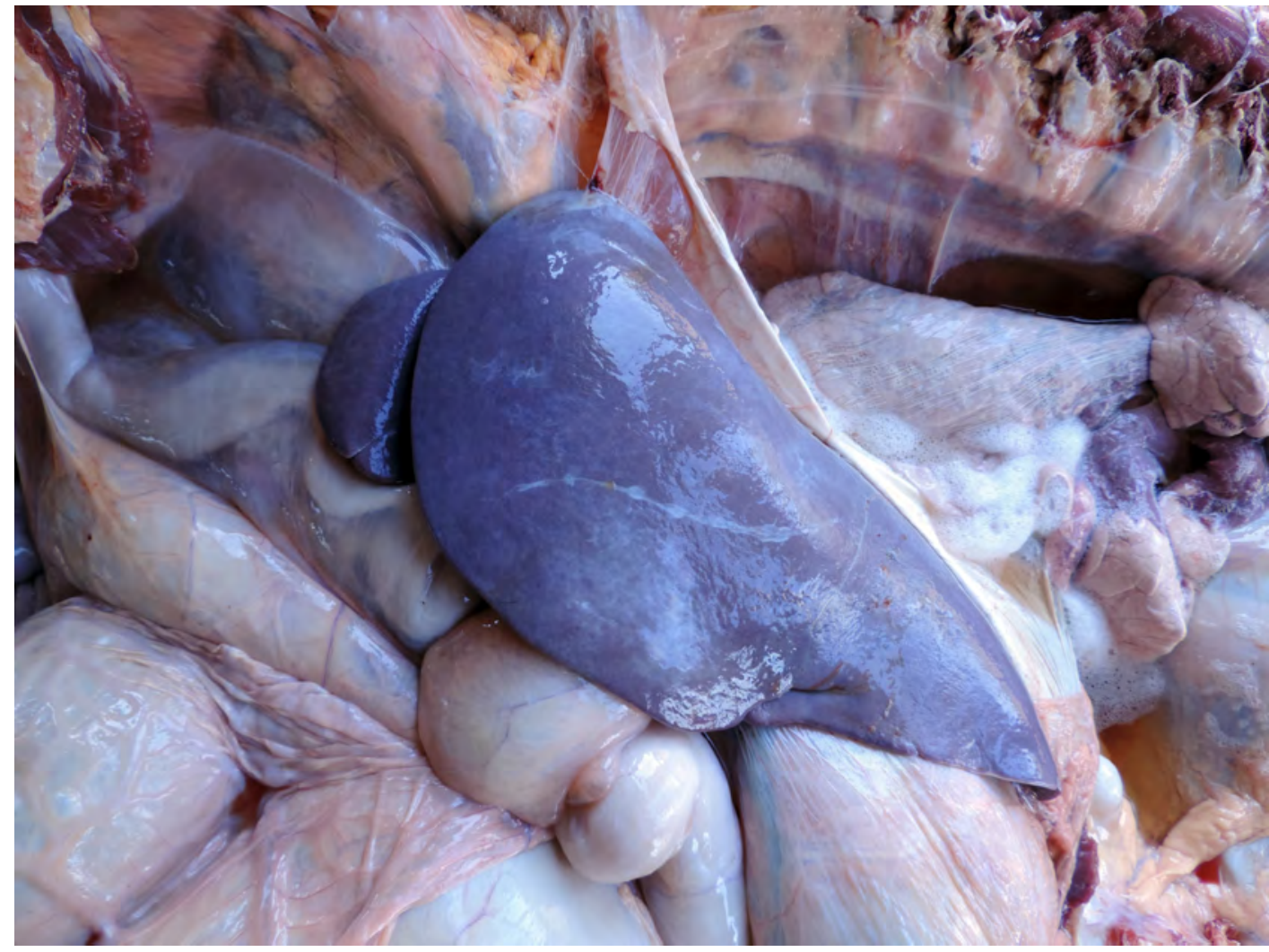

Figure 2

Brazilian Journal of Veterinary Pathology. www.bjvp.org.br . All rights reserved 2007-2021. 
Diagnostic exercise From The Latin Comparative Pathology Group and

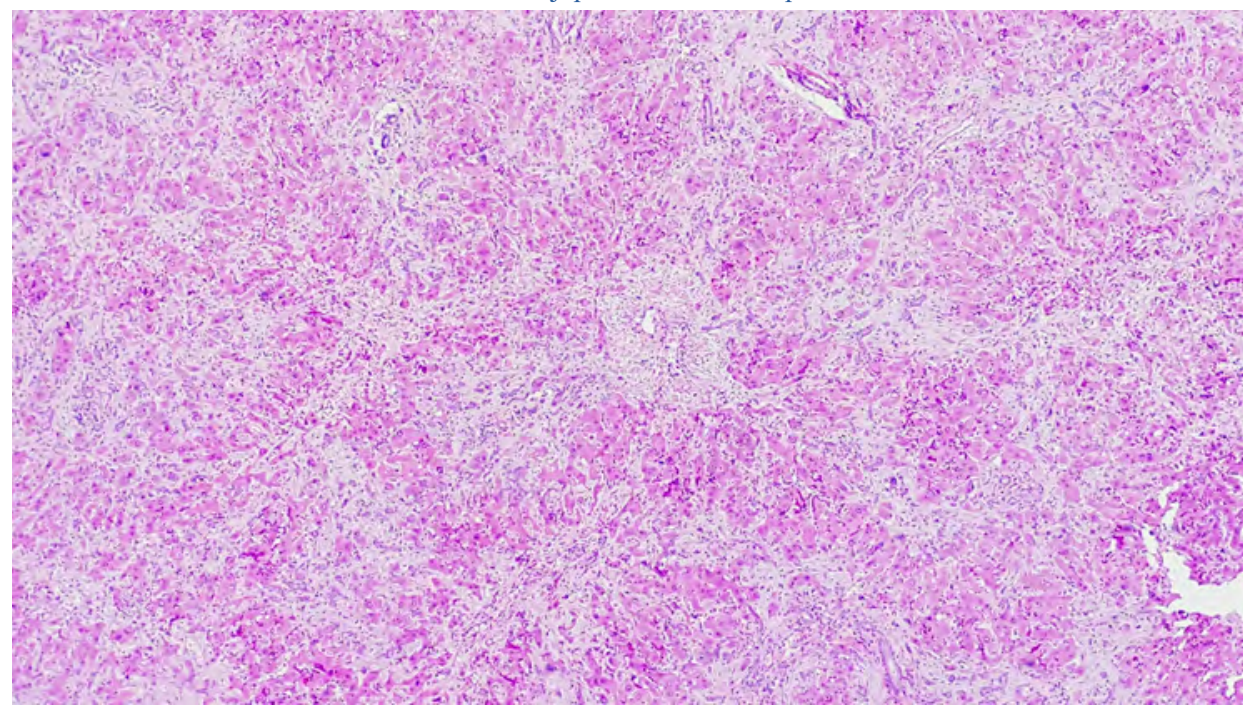

Figure 3

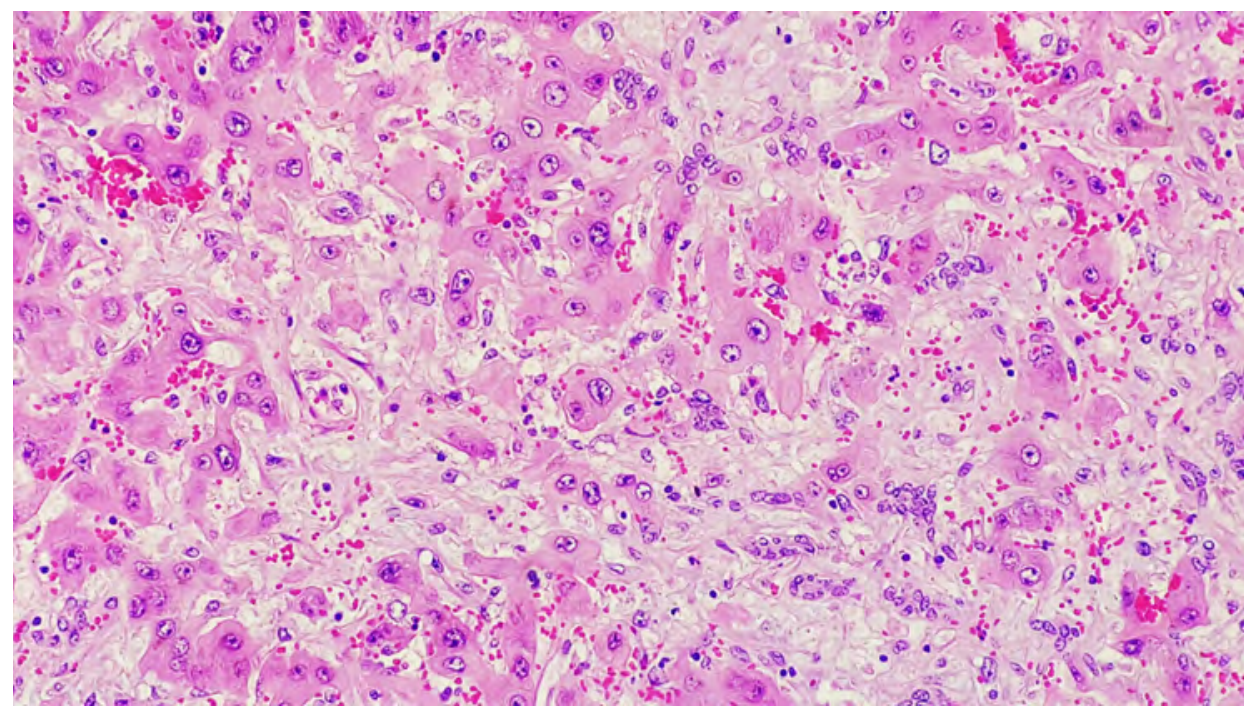

Figure 4

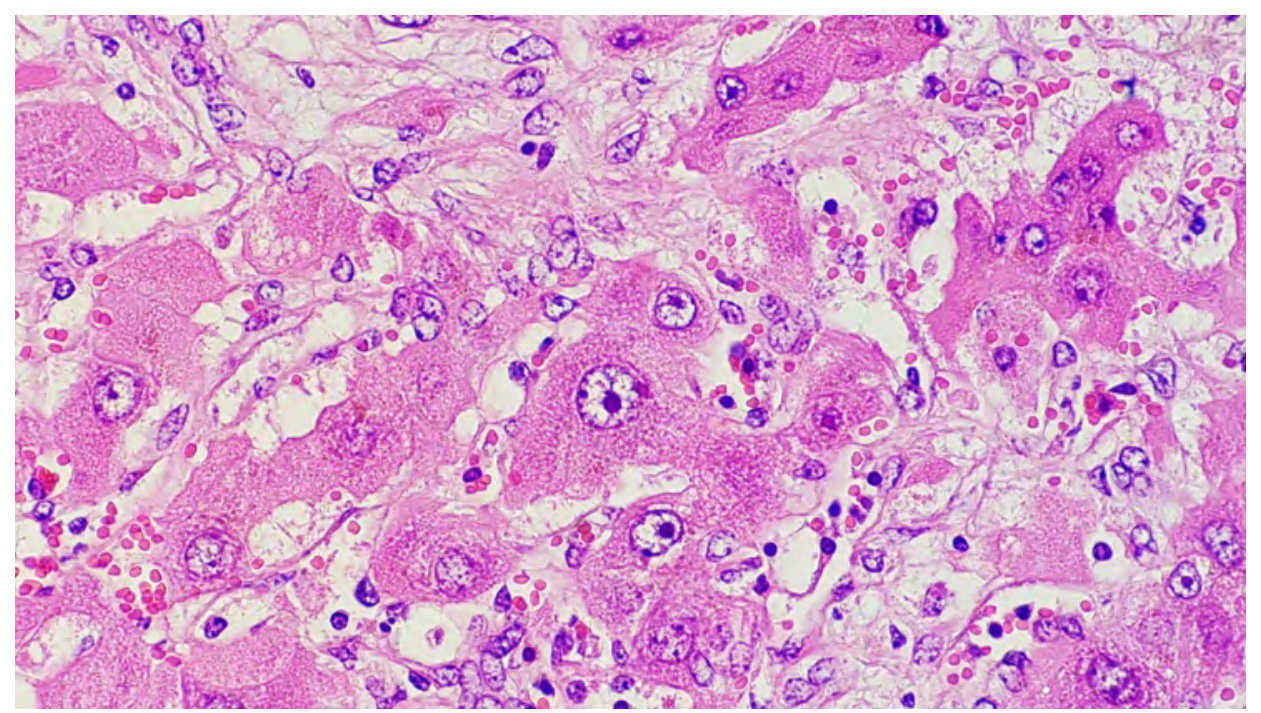

Figure 5

Brazilian Journal of Veterinary Pathology. www.bjvp.org.br . All rights reserved 2007-2021. 
- Diagnosis: Liver, severe periportal and bridging fibrosis, with biliary duct hyperplasia, hepatocellular loss, and hepatocellular karyomegaly and megalocytosis

- $\quad$ Typical gross findings: Chronic pyrrolizidine alkaloid (PA) toxicosis induces hepatic fibrosis in cattle, eventually leading to end-stage liver disease and chronic liver failure. The affected liver is typically reduced in size, grayish, and firm, with a smooth capsular surface. Regenerative nodules are uncommon. Chronic liver failure may lead to extra-hepatic necropsy findings, particularly generalized edema (subcutaneous, mesenteric and cavitary). The cavitary effusion is translucent and colorless to yellowish, with low density (pure transudate) (Cullen and Stalker 2015).

- Typical microscopic findings: Three important histologic features are indicative of chronic PA toxicosis: marked fibrosis, biliary duct hyperplasia, and hepatocellular karyomegaly/megalocytosis (Cullen and Stalker 2015). The encephalic lesions are secondary to hyperammonemia. In cattle, these are characterized by moderate to severe spongiform change, predominantly at the white and gray matter junction. It does not cause macroscopic brain changes (Cantile and Youssef 2015).

\section{Discussion:}

PAs are found in several different plants around the world (namely plants from the Boraginaceae, Asteraceae [Compositae] and Leguminosae [Fabaceae] families) and, when ingested during a long period, they induce chronic hepatic fibrosis in several animals, which eventually evolves to end-stage liver disease and chronic liver failure. Acute toxicosis - characterized by centrilobular hepatic necrosis - is reported; however, it is considered uncommon. Some examples of PA-containing plants that are important for domestic species include Senecio, Crotalaria, Heliotropium, Amsinckia, Echium and Cynoglossum (Cullen and Stalker 2015, JPC WSC 2020-2021). In this particular case, Senecio brasiliensis was identified in the pasture in which affected animals were grazing. PA-containing plants are unpalatable, which would theoretically make the intoxication uncommon. However, starving animals - like cattle kept on poor winter pasture - tend to eat the plant and develop the disease. Other forms of intoxication include forage and grain contamination with leaves, flowers, and seeds from PA-containing plants (Barros et al. 1992, Cullen and Stalker 2015). More than 350 PAs have been identified, and several toxic plants contain more than one of the alkaloids. PAs are biotransformed by $\mathrm{P} 450$ cytochrome within zone 3 hepatocytes, which gives origin to dehydropyrrolizidine (DHP) alkaloids in the liver (Cullen and Stalker 2015, JPC WSC 2020-2021). These alkaloids bind to the hepatocyte DNA and inhibit DNA synthesis and mitosis; however, some hepatocytes are able to replicate their DNA without undergoing mitosis. This results in karyomegaly and megalocytosis, which are observed in histologic slides and assist in the diagnosis (Cullen and Stalker 2015).
Additionally, DHP alkaloid DNA adduct formation is a common pathway for the carcinogenic activity of PA. Biliary hyperplasia is an important histologic feature and is part of the hepatic response to chronic liver injury. In this case, it is probably stimulated by the fact that adult hepatocytes are not responding to regenerative stimuli (Cullen and Stalker 2015). Periportal fibroplasia varies with species in chronic exposure, and it tends to be marked in cattle developing the disease. In fact, cattle often develop a dissecting pattern of fibrosis, in which collagen and fibroblasts dissect through the liver sinusoids, isolating individual cells or cell groups and contributing to liver failure (Barros et al. 1992, Cullen and Stalker 2015). Among farm animals, pigs are the most susceptible. Horses and cattle are of intermediate susceptibility, and sheep are the most resistant (Cullen and Stalker 2015). In Brazil, sheep are therefore generally used as a method of controlling Senecio in the pasture (Barros et al. 1992). Human intoxication is a problem in some areas of the world, where PA-containing plants are eaten or used as part of herbal medicine (Cullen and Stalker 2015, JPC WSC 2020-2021). Common clinical signs of chronic PA toxicosis in cattle include progressive weight loss, chronic diarrhea, lethargy, anorexia, tenesmus often followed by rectal prolapse, and rough hair coat. Affected animals may have abdominal distention (ascites) and subcutaneous edema. Finally, neurologic signs may manifest secondary to hepatic encephalopathy. Some uncommon signs include icterus and photodermatitis (Barros et al. 1992). The edema is attributed to hypoproteinemia induced by chronic liver failure. In addition, the hepatic fibrosis, when severe enough, may impair the blood flow through the liver, increasing the hydrostatic pressure within the portal circulation, which is another mechanism for ascites in these animals (Cullen and Stalker 2015). Hepatic encephalopathy is a common feature of chronic liver diseases, such as PA toxicosis (Barros et al. 1992, Cullen and Stalker 2015). It is attributed to the high levels of circulating ammonia, which is toxic to the CNS cells. Hepatic encephalopathy is histologically different between species; in ruminants, it produces a spongiform change predominantly at the white and gray matter junction (Cantile and Youssef 2015).

\section{References}

1. Cantile, C. and Youssef, S. Nervous system. In: Maxie M.G. editor. Jubb, Kennedy, and Palmer's Pathology of Domestic Animals. V2, 6th edition. Saint Louis: Elsevier; 2015. p. 344

2. Cullen, J.M. and Stalker, M.J. Liver and biliary system. In: Maxie M.G. (Ed) Jubb, Kennedy and Palmer's Pathology of Domestic Animals. V2, 6th edition, Elsevier. Saint Louis. 2015. p.336-8.

3. Barros, CS; Driemeier D, Pilati C, Barros S.S., Castilhos L.M. Senecio spp. poisoning in cattle in southern Brazil. Vet. .Human Toxicol. 1992; 34(3):241-6.

4. Joint Pathology Center Wednesday Slide Conference 2020-2021. Conference 8, case 2. Available at: $<$ https:// www.askjpc.org/wsco/wsc/wsc20/20WSC08.pdf>. 